Review

\title{
Trust Your Gut: Galvanizing Nutritional Interest in Intestinal Cholesterol Metabolism for Protection Against Cardiovascular Diseases
}

\author{
Casey J. Wegner, Bohkyung Kim and Jiyoung Lee * \\ Department of Nutritional Sciences, University of Connecticut, 216 Advanced Technology Laboratory \\ Building, 1392 Storrs Road, Storrs, CT 06269, USA; E-Mails: casey.wegner@uconn.edu (C.J.W.); \\ bohkyung.kim@uconn.edu (B.K.) \\ * Author to whom correspondence should be addressed; E-Mail: Ji-Young.Lee@uconn.edu; \\ Tel.: +1-860-486-1827; Fax: +1-860-486-3674.
}

Received: 14 December 2012; in revised form: 9 January 2013 / Accepted: 11 January 2013 / Published: 16 January 2013

\begin{abstract}
Recent studies have demonstrated that the intestine is a key target organ for overall health and longevity. Complementing these studies is the discovery of the trans-intestinal cholesterol efflux pathway and the emerging role of the intestine in reverse cholesterol transport. The surfacing dynamics of the regulation of cholesterol metabolism in the intestine provides an attractive platform for intestine-specific nutritional intervention strategies to lower blood cholesterol levels for protection against cardiovascular diseases. Notably, there is mounting evidence that stimulation of pathways associated with calorie restriction may have a large effect on the regulation of cholesterol removal by the intestine. However, intestinal energy metabolism, specifically the idiosyncrasies surrounding intestinal responses to energy deprivation, is poorly understood. The goal of this paper is to review recent insights into cholesterol regulation by the intestine and to discuss the potential for positive regulation of intestine-driven cholesterol removal through the nutritional induction of pathways associated with calorie restriction.
\end{abstract}

Keywords: trans-intestinal cholesterol efflux (TICE); reverse cholesterol transport (RCT); intestine; liver X receptor (LXR); peroxisome proliferator-activated receptor $\delta(\operatorname{PPAR} \delta)$; calorie restriction; sirtuin; fasting; $\mathrm{NAD}(+)$ 


\section{Introduction}

Elevated low-density lipoprotein (LDL) cholesterol in circulation can lead to cholesterol deposition and crystallization within artery walls, which is recognized as the hallmark of early atherosclerotic lesions [1]. It has been estimated that one in every six deaths in the US is attributed to coronary heart disease (CHD) [2]. As CHD continues to burden developed countries, the need for more effective strategies to lower plasma cholesterol levels becomes increasingly apparent. Current hypocholesterolemic strategies largely focus on either lowering circulating LDL cholesterol or promoting reverse cholesterol transport (RCT), a process classically thought to involve the delivery of excess cholesterol from the periphery to the liver for subsequent biliary excretion. However, recent evidence demonstrates that the intestine is host to novel pathways capable of modulating whole body cholesterol metabolism. Targeting the intestine to lower plasma cholesterol concentrations is therapeutically attractive because stimulation of hepatic cholesterol secretion to bile can facilitate gallstone formation $[3,4]$.

The role of the intestine in the regulation of whole body cholesterol status has been historically underestimated. The recent elucidation of trans-intestinal cholesterol efflux (TICE) [5,6] and intestinal contributions to high-density lipoprotein (HDL) biogenesis [7] and RCT [8,9] make the gut an excellent nutritional target for CHD prevention. However, the metabolic states and biological processes that regulate cholesterol homeostatic pathways in the intestine are poorly understood. The goals of this review are to discuss recent understandings of the role of the intestine in the removal of circulating cholesterol and to examine the interface between intestine-specific cholesterol regulation targets and cellular responses associated with calorie restriction.

\section{Trans-Intestinal Cholesterol Efflux (TICE)}

It has long been accepted that cholesterol removal from the periphery, and subsequently the body, is confined to hepatobiliary excretion via HDL-mediated RCT. However, overlooked evidence dating back as far as the early 20th century has suggested a non-biliary route of cholesterol excretion [10,11]. Recent observations have renewed focus on this possibility [12]. Using ATP-binding cassette transporter A1 (ABCA1) knockout $\left(\mathrm{Abcal}^{-/-}\right)$mice, which have nearly undetectable plasma HDL cholesterol levels, Groen et al. [13] showed that a lack of HDL did not affect hepatobiliary cholesterol secretion and fecal excretion of neutral and acidic sterols. Plosch et al. [14] and Kruit et al. [15] also demonstrated that increased fecal neutral sterol loss by the activation of liver X receptor (LXR) could not be solely attributed to increased hepatobiliary cholesterol excretion. More recently, liver-specific acyl CoA:cholesterol acyltransferase 2 (ACAT2) depletion in mice paradoxically resulted in increased fecal sterol loss without increases in biliary cholesterol excretion [6]. This collection of increasingly confounding evidence has led to the recent elucidation of trans-intestinal cholesterol efflux (TICE).

TICE refers to the flux of cholesterol from circulating lipoproteins through the intestine and into the lumen for subsequent excretion or reabsorption [16-18]. TICE has been shown to occur throughout the small intestine with the greatest percentage of TICE occurring in the proximal intestine [5]. To gain insight into the role of HDL in TICE, HDL particles with radiolabeled cholesterol were injected into mice genetically deficient of ABCA1 and scavenger receptor class B type 1 (SR-B1), which have extremely low HDL cholesterol levels and a defect in HDL clearance [19]. Both wild-type and the 
double knockout mice failed to take up and secrete HDL-derived cholesterol via TICE, suggesting a minimal contribution of HDL to TICE. Although the specific cholesterol donor(s) for TICE have yet to be determined, apolipoprotein B-containing lipoproteins are likely the cholesterol donors for TICE [16]. The ability to study TICE has been enabled by innovative surgical techniques (i.e., intestinal perfusions [5] and biliary diversions [20]) and genetic mouse models with drastically reduced biliary cholesterol excretion such as mice with liver-specific overexpression of Niemann-Pick C1-like 1 (NPC1L1) [20,21] and multidrug resistance P-glycoprotein 2 (Mdr2) deficient mice [15]. It has been estimated that TICE accounts for $\sim 20 \%-33 \%$ of basal fecal sterol losses in both humans [22,23] and mice [15,24]. Importantly, using murine models it has been shown that the non-biliary TICE pathway can be stimulated to become quantitatively more important than hepatobiliary cholesterol removal [24,25]. Activation of $\operatorname{LXR}[14,20,24]$ and peroxisome proliferator-activated receptor $\delta$ (PPAR $\delta$ ) [25], ezetimibe administration [26] and fasting [27] are known to stimulate TICE. The therapeutic implications of TICE induction were further highlighted by the finding that TICE can participate in macrophage RCT in mice [20]. Since HDL does not directly contribute to TICE in mice [19], this finding by Temel et al. [20] also challenges the selectivity of HDL for macrophage-derived RCT.

Despite evidence of TICE stimulation suggested by several studies, the precise underlying mechanisms and pathways that induce TICE are largely unknown. In addition to the identification of cholesterol donors for TICE, cholesterol transporters in the apical and basolateral membrane of enterocytes, intracellular mechanisms and mediators for cholesterol trafficking and lumenal cholesterol acceptors still need to be determined to gain better insight into the overall TICE process. The use of nutritional interventions that offer well-characterized alterations in metabolism may be a logical approach to resolve these TICE unknowns. Identification of the metabolic controls and corresponding physiological events that stimulate TICE will highlight key cellular components involved in TICE and help elucidate additional therapeutic targets. Importantly, it needs to be determined if intestine-specific intervention strategies can lead to TICE induction and subsequent cholesterol removal. Intestine-specific regulation of cholesterol removal would offer nutritional targets in an organ that bypasses many of the bioavailability concerns that plague dietary nutrients and bioactive components. Preliminary evidence described above suggests that intestine-specific strategies are a viable option for cholesterol removal and this evidence will be discussed next.

\section{Intestinal Contributions to RCT \& HDL Biogenesis}

At the molecular level, synthetic agonists of LXRs are arguably the most effective activators of RCT. LXRs are nuclear receptors that transcriptionally regulate lipid homeostasis and cholesterol efflux in the liver, intestine and macrophages in response to cellular sterol levels [8,28]. Activation of hepatic LXR leads to increased biliary cholesterol excretion, while also inducing hepatic de novo lipogenesis [9]. Therefore, cholesterol-lowering strategies have steered away from targeted stimulation of RCT via enhanced biliary cholesterol excretion considering that this approach also promotes cholesterol gallstone disease [3] and hepatic steatosis [4]. Alternatively, recent findings have shown that intestine-specific LXR activation stimulates cholesterol transport from macrophage to feces via a process called "macrophage RCT" and circumvents the side effects of hepatic LXR activation such as 
increased lipogenesis [8,9]. GW6340, an intestine-specific LXR agonist, stimulated macrophage RCT by $\sim 52 \%$ in mice [9]. Lo Sasso et al. [8] also demonstrated that intestinal LXR activation reduced atherosclerosis development in LDL receptor knockout mice and increased RCT in mice with intestine-specific, constitutively activated LXR $\alpha$.

The intestine also plays a critical role in the biogenesis of HDL. ABCA1, a LXR target gene expressed on the basolateral membrane of enterocytes, is a ubiquitous, membrane-bound transporter that mediates cellular cholesterol and phospholipid efflux to lipid-free or lipid-poor apolipoprotein AI (apoA-I) for nascent HDL formation [29]. Murine intestinal ABCA1 is responsible for $\sim 30 \%$ of the steady-state HDL cholesterol in plasma [7] and increased plasma HDL cholesterol via treatment with GW3965, a synthetic LXR agonist, was completely nullified in mice lacking intestinal ABCA1 [30]. Furthermore, intestine-specific constitutive activation of $\mathrm{LXR} \alpha$ in mice led to increased intestinal ABCA1 expression with a concomitant increase in HDL biogenesis [8]. Cardio-protective effects from simply increasing plasma HDL cholesterol levels has proved controversial, so a premium should be placed on HDL-raising therapies that subsequently promote cholesterol excretion [31]. In this context, intestine-specific LXR activation to increase nascent HDL formation holds great promise.

Activation of PPAR $\delta$ has also been shown to stimulate RCT via an intestine-specific mechanism of action [32,33]. In general, PPARs are a subgroup of ligand-activated transcription factors that regulate a variety of genes involved in lipid and energy metabolism [34,35]. Of the several PPAR subtypes, PPAR $\delta$ is the least understood, but the physiological role of PPAR $\delta$ is believed to involve glucose and fatty acid metabolism [35,36]. The recent development of PPAR $\delta$ agonists has led to the discovery of increased HDL cholesterol levels and RCT upon the activation of PPAR $\delta$ in insulin resistant mice [37] and monkeys [38]. Moreover, increased HDL cholesterol levels were observed in healthy human subjects when a PPAR $\delta$ agonist was administered [39]. Like LXR, PPAR $\delta$ has been separately implicated in intestine-specific TICE stimulation [25] and RCT [32]. However, enhanced RCT from PPAR $\delta$ activation has been attributed to reduced intestinal reabsorption of HDL-derived biliary cholesterol [32]. The reduction in intestinal cholesterol absorption by PPAR $\delta$ activation is at least partly due to decreased expression of intestinal NPC1L1 [32,33]. NPC1L1 is a cholesterol transporter that is highly expressed on the brush border of enterocytes and it is critical for intestinal cholesterol absorption [40]. Van der Veen et al. [33] documented that PPAR $\delta$-induced decreases in intestinal NPC1L1 expression corresponded to increased fecal neutral sterol excretion, which persisted even when increases in HDL cholesterol levels were nullified in mice lacking ABCA1. Briand et al. [32] showed a similar stimulation of RCT after treatment with ezetimibe, a specific NPC1L1 inhibitor. Interestingly, ezetimibe was also shown to increase TICE via a mechanism that could not be solely attributed to its inhibitory action on intestinal cholesterol absorption [26].

Clearly, the intestine has emerged as a dynamic organ with tremendous therapeutic potential for lowering cholesterol. However, the cellular factors that promote atheroprotection via TICE and/or intestine-driven RCT remain elusive. As discussed above, pharmacological activation of both LXR and $\operatorname{PPAR} \delta$ has been reported to independently stimulate each of these intestinal pathways for cholesterol removal. Therefore, understanding metabolic controls that promote activation of these targets may help unveil the mechanisms for intestine-specific cholesterol removal and elucidate additional therapeutic targets for cholesterol reduction via the intestine. 


\section{Energy Deprivation and Intestinal Cholesterol Regulation}

In general, the connection between energy deprivation and the gut's pivotal role in overall health and longevity was recently demonstrated in Drosophila melanogaster [41-43]. Intestine-specific overexpression of the Drosophila peroxisome proliferator-activated receptor $\gamma$ coactivator-1 $\alpha$ (PGC-1 $\alpha$ ) homolog, a key regulator of energy metabolism induced by energy deprivation, delayed age-related deterioration of intestinal homeostasis and extended life span of the organism. Other studies in C. elegans [44] and mice [45] also support the notion that enhanced intestinal function/homeostasis increases lifespan.

The metabolic dichotomy between fed and fasted states in the intestine may offer a useful tool to study the metabolic pathways related to TICE and intestinal contributions to whole body cholesterol homeostasis. In particular, the metabolic responses to energy deprivation are an evolutionary conserved set of highly regulated biological events that promote the mobilization of stored energy and enhance oxidative metabolism [46-48]. Studies on energy deprivation responses at an organismal level are often carried out using caloric restriction (CR), which is defined as a $20 \%-40 \%$ caloric reduction versus ad libitum feeding [49,50]. CR has been shown to extend lifespan and protect against age-related diseases in a number of organisms, including mammals [50-52]. Notably, CR has been shown to mitigate the risk for atherosclerosis development in humans [53]. The hallmark signatures of $\mathrm{CR}$ in mammals reflect the reciprocal activation of AMP-activated protein kinase (AMPK) and $\mathrm{NAD}^{+}$-dependent sirtuins (SIRTs) [48,54-57]. AMPK responds to increased cellular AMP/ATP ratios by increasing cellular $\mathrm{NAD}^{+}$[56]. Interestingly, AMPK activation has been shown to mediate the CR-like effects of PPAR $\delta$ agonists [36]. It is well understood that cells have evolved to use $\mathrm{NAD}^{+}$as a nutrient sensor and determinant of cellular metabolism and survival $[58,59]$. NAD ${ }^{+}$levels have been shown to rise in numerous tissues in response to fasting, $\mathrm{CR}$ and exercise, while high-fat diets reduce the $\mathrm{NAD}^{+}$levels in mice [60].

Several metabolic responses associated with energy deprivation/CR are mediated by $\mathrm{NAD}^{+}$-dependent mammalian orthologs of lower eukaryotic Sir2: SIRTs [61]. The seven mammalian SIRTs, i.e., SIRT1-7, are an unusual and conserved class of deacetylases and mono-ADP-ribosyltransferases that use $\mathrm{NAD}^{+}$ as a co-substrate to regulate metabolic processes, including lipid metabolism [47,50]. SIRTs can regulate cellular activities by deacetylating a wide array of histone and non-histone proteins in response to cellular energy deficits [60]. SIRT1, the most studied mammalian SIRT, has been shown to regulate a number of transcription factors and proteins involved in cholesterol and lipid metabolism, including PGC-1 $\alpha$ [48,62], PPAR $\alpha$ and $\gamma$ [47,63,64], farnesoid X receptor (FXR) [65], sterol regulatory element-binding proteins (SREBPs) [66,67], cholesterol 7 $\alpha$-hydroxylase (CYP7A1) [68] and LXR [28]. Significant decreases in plasma total and LDL cholesterol concentrations were observed in transgenic mice overexpressing SIRT1 [69], while SIRT1 knockout (Sirt1 ${ }^{-1}$ ) mice showed blunted HDL cholesterol increases after an 8-day LXR agonist (T0901317) administration [28]. However, contributions of SIRT1 to intestine-specific regulation of cholesterol metabolism remain to be determined. 


\subsection{Prolonged Fasting Stimulates TICE}

A range of evidence exists that suggests many of the cellular processes associated with energy deprivation and CR may influence intestine-specific regulation of cholesterol removal. Sokolovic et al. [27] demonstrated increases in intestinal cholesterol levels and TICE during prolonged fasting (48 h) in mice. Similarly, increased output of biliary bile salts, phospholipids and cholesterol were also observed during fasting. As corresponding increases in fecal neutral sterols were not observed during fasting in this study, the physiological significance of increased TICE during energy deprivation in regulating whole body cholesterol homeostasis is not clear. Nonetheless, the findings highlight that energy status in the intestine is an important factor to modulate intestinal cholesterol flux. Elevated TICE during fasting may be partly explained by increases in biliary outputs of bile salts and phospholipids as their presence in the intestinal lumen has been shown to stimulate TICE by functioning as cholesterol acceptors [5]. Alternatively, Danielsen et al. [70] provided evidence for the role of enterocytes in fasting-induced TICE by demonstrating that apoA-I is secreted apically from enterocytes into the lumen of porcine small intestines during fasting. The study also showed bile-dependent deposition of apically secreted, lipid-free/poor apoA-I in the brush border, and microvillar apoA-I was shown to be associated with cholesterol. The authors conjecture that this deposited apoA-I is well suited to participate in TICE [70]. ApoA-I acts as a cholesterol acceptor by interacting with ABCA1 [71-73]. Therefore, for the microvillar apoA-I to be a functional cholesterol acceptor in the lumen of the intestine, an unknown transporter on the apical membrane of enterocytes is likely necessary to interact with apoA-I. Furthermore, the capacity of apoA-I to draw cholesterol from enterocytes to the intestinal lumen may not be quantitatively significant. Thus, the contributions of microvillar apoA-I to TICE as a cholesterol acceptor need further investigation.

While this review discusses evidence suggesting that processes associated with energy deprivation can positively regulate intestine-specific cholesterol removal, it should be noted that increases in TICE were also observed in mice fed Western-type and high fat diets [74]. The reasons for this ambivalent regulation of TICE by energy deprivation as well as Western-type diets containing high fats and cholesterol remain to be determined. In general, TICE stimulation resulting from diets rich in cholesterol and lipids is likely related to the body's effort to remove excess cholesterol for maintaining cholesterol homeostasis. In contrast, given that adipose tissue contains $15 \%-20 \%$ of the body's cholesterol in normal individuals and more than 50\% in obese subjects [75], increased cholesterol mobilization as a consequence of triglyceride hydrolysis in adipose tissue may contribute to the increased intestinal cholesterol uptake and subsequent TICE during fasting. This ambivalent behavior of TICE could be problematic for nutritional interventions, yet pursuing intervention strategies that are already known to positively influence cholesterol profiles and protect against CVD (i.e., inducing energy deprivation pathways) may be a logical first-step approach.

\subsection{PPAR $\delta$ Agonists and CR}

PPAR $\delta$ agonists induce metabolic changes consistent with $\mathrm{CR}$ and prolonged exercise [35]. Following short-term exposure to a PPAR $\delta$ agonist, a decrease in cellular energy status and subsequent AMPK activation were observed in human myotubes [36]. Interestingly, PPAR $\delta$ is highly expressed in 
the intestine and PPAR $\delta$ mRNA levels have been shown to increase in fasted mice [76]. Furthermore, activation of PPAR $\delta$ has been shown to induce TICE without influencing biliary cholesterol excretion [25]. PPAR $\delta$ agonists have been shown to promote RCT and reduce atherogenic inflammation $[25,32,77,78]$. Thus, it appears that PPAR $\delta$ may play an athero-protective role at least in part by enhancing TICE and RCT in the intestine via the modulation of metabolic pathways similarly to CR. However, intestine-specific induction of PPAR $\delta$ in relation to energy deprivation has yet to be assessed.

\subsection{Positive Regulation of LXR by SIRT1}

Studies have shown that intestine-specific LXR activation stimulates RCT/TICE [8,14,20,24]. LXR activation is generally associated with the fed state, but recent studies have paradoxically demonstrated positive regulation of LXR by SIRT1. Li et al. [28] showed that LXR acetylation occurs at a single conserved lysine residue (K432 in LXR $\alpha$ and K433 in LXR $\beta$ ) and loss of SIRT1 in vivo leads to decreased expression of LXR target genes. In this study, Sirt $1^{-/-}$mice had decreased plasma HDL cholesterol levels and peritoneal macrophages and hepatocytes from Sirt $1^{-1-}$ mice showed a reduction in apoA-I mediated cholesterol efflux [79,80]. A recent study by Defour et al. [81] also demonstrated that SIRT1 deacetylates LXR $\alpha$ and LXR $\beta$ in human skeletal muscle. It is tempting to speculate that the surge in intestinal cholesterol levels during fasting [27] offers a scenario where active LXR, and subsequent cholesterol efflux, could be positively regulated by SIRT1 during cellular energy deficits. Regulation of LXR by SIRT1 in the intestine has yet to be addressed.

\section{Nutritional Induction of Energy Deprivation Pathways}

The intestine has emerged as an organ capable of stimulating RCT and coordinating the uptake, trafficking and efflux of circulating cholesterol, i.e., TICE. The evidence discussed above suggests that metabolic pathways associated with $\mathrm{CR} /$ energy deprivation can similarly promote TICE and/or intestine-specific RCT stimulation. However, unlike other tissues that make significant contributions to lipid metabolism, the cellular influences of CR/energy deprivation on the intestine are poorly understood. Recent studies using transcriptomic profiling suggested that the small intestine exhibits a biphasic metabolic response to fasting that differs from the well-characterized and progressive adaptive response to fasting by the liver $[82,83]$. This makes sense considering the unique energetic preference for glutamine by the intestine [84]. Therefore, the influence of CR on intestine-specific cholesterol removal pathways needs to be assessed.

CR-mimetics and $\mathrm{NAD}^{+}$precursors are an attractive means to study metabolic pathways that are triggered by energy deprivation in the gut. For instance, $\mathrm{NAD}^{+}$precursors such as nicotinamide mononucleotide $(\mathrm{NMN})$ and nicotinamide riboside $(\mathrm{NR})$ hold great nutritional promise for lowering plasma cholesterol by increasing $\mathrm{NAD}^{+}$and subsequently activating pathways associated with CR/energy deprivation via SIRT1 [85,86]. Dietary supplementation of NR, a compound found naturally in milk, was shown to prevent diet-induced obesity and significantly reduce plasma total cholesterol levels in C57BL/6J mice fed a high fat diet [85]. Similarly, daily i.p. injections of NMN $(500 \mathrm{mg} / \mathrm{kg})$ for 11 days ameliorated high fat diet-induced hypercholesterolemia in age-induced Type 2 diabetic mice [86]. Due to these findings, speculations have begun to circulate regarding the 
unclear mechanisms behind niacin's potent hypolipidemic effects. Niacin, in the form of nicotinic acid, is another $\mathrm{NAD}^{+}$precursor and potent serum cholesterol-lowering agent that exhibits cardioprotective effects [87]. The original observation concerning the cholesterol-lowering effect of nicotinic acid by Altschul et al. [88] noted that similar cholesterol-lowering effects were not observed with nicotinamide treatments. Interestingly, nicotinamide, a product of SIRT deacetylation reactions, is a known feedback inhibitor of SIRT activity [89]. Overall, $\mathrm{NAD}^{+}$precursors such as NR and NMN are promising candidates for cholesterol-lowering strategies that do not produce flushing, a severe side effect of nicotinic acid [85]. Yet, the effect of NR and NMN on intestine-specific cholesterol regulatory pathways and corresponding protection against CVD has yet to be assessed.

The red wine polyphenol and CR mimetic, resveratrol has proved to be a small-molecule activator of AMPK and SIRT1 in vitro and in vivo [90,91]. A number of recent studies have truly begun to unravel the mechanistic influences of resveratrol [92,93]. Human trials have demonstrated mixed results concerning the effect of resveratrol on various metabolic and lipid parameters [94,95]. However, the specific role of resveratrol in the regulation of intestine-specific lipid/cholesterol metabolism and fecal sterol excretion remains to be determined. Additionally, a number of other dietary polyphenols have been suggested to regulate SIRT1 and the pathways associated with CR [96]. Future research into intestinal SIRT1 modulation by polyphenols could help elucidate the mechanism underlying hypocholesterolemic mechanisms of action for many of these highly consumed bioactives.

\section{Conclusions}

In support of the overall health promoting prominence of the intestine, recent findings have unveiled the critical roles of the intestine in the regulation of whole body cholesterol homeostasis particularly by enhancing TICE and RCT. For the field of nutrition, the discovery of novel cholesterol regulatory pathways in the intestine undoubtedly offers an unexplored platform for intestine-specific intervention strategies to lower blood cholesterol levels for protection against CVD.

\section{Acknowledgments}

This work was supported by funds from USDA Hatch and College of Agriculture and Natural Resources to J. Lee.

\section{Conflict of Interest}

The authors declare no conflict of interest.

\section{References}

1. Duewell, P.; Kono, H.; Rayner, K.J.; Sirois, C.M.; Vladimer, G.; Bauernfeind, F.G.; Abela, G.S.; Franchi, L.; Nunez, G.; Schnurr, M.; et al. NLRP3 inflammasomes are required for atherogenesis and activated by cholesterol crystals. Nature 2010, 464, 1357-1361.

2. Roger, V.L.; Go, A.S.; Lloyd-Jones, D.M.; Adams, R.J.; Berry, J.D.; Brown, T.M.; Carnethon, M.R.; Dai, S.; de Simone, G.; Ford, E.S.; et al. Heart disease and stroke statistics-2011 update: A report from the american heart association. Circulation 2011, 123, e18-e209. 
3. Grunhage, F.; Acalovschi, M.; Tirziu, S.; Walier, M.; Wienker, T.F.; Ciocan, A.; Mosteanu, O.; Sauerbruch, T.; Lammert, F. Increased gallstone risk in humans conferred by common variant of hepatic ATP-binding cassette transporter for cholesterol. Hepatology 2007, 46, 793-801.

4. Grefhorst, A.; Elzinga, B.M.; Voshol, P.J.; Plosch, T.; Kok, T.; Bloks, V.W.; van der Sluijs, F.H.; Havekes, L.M.; Romijn, J.A.; Verkade, H.J.; et al. Stimulation of lipogenesis by pharmacological activation of the liver $\mathrm{X}$ receptor leads to production of large, triglyceride-rich very low density lipoprotein particles. J. Biol. Chem. 2002, 277, 34182-34190.

5. Van der Velde, A.E.; Vrins, C.L.; van den Oever, K.; Kunne, C.; Oude Elferink, R.P.; Kuipers, F.; Groen, A.K. Direct intestinal cholesterol secretion contributes significantly to total fecal neutral sterol excretion in mice. Gastroenterology 2007, 133, 967-975.

6. Brown, J.M.; Bell, T.A., III; Alger, H.M.; Sawyer, J.K.; Smith, T.L.; Kelley, K.; Shah, R.; Wilson, M.D.; Davis, M.A.; Lee, R.G.; et al. Targeted depletion of hepatic ACAT2-driven cholesterol esterification reveals a non-biliary route for fecal neutral sterol loss. J. Biol. Chem. 2008, 283, 10522-10534.

7. Brunham, L.R.; Kruit, J.K.; Iqbal, J.; Fievet, C.; Timmins, J.M.; Pape, T.D.; Coburn, B.A.; Bissada, N.; Staels, B.; Groen, A.K.; et al. Intestinal ABCA1 directly contributes to HDL biogenesis in vivo. J. Clin. Invest. 2006, 116, 1052-1062.

8. Lo Sasso, G.; Murzilli, S.; Salvatore, L.; D’Errico, I.; Petruzzelli, M.; Conca, P.; Jiang, Z.Y.; Calabresi, L.; Parini, P.; Moschetta, A. Intestinal specific LXR activation stimulates reverse cholesterol transport and protects from atherosclerosis. Cell Metab. 2010, 12, 187-193.

9. Yasuda, T.; Grillot, D.; Billheimer, J.T.; Briand, F.; Delerive, P.; Huet, S.; Rader, D.J. Tissue-specific liver $\mathrm{X}$ receptor activation promotes macrophage reverse cholesterol transport in vivo. Arterioscler. Thromb. Vasc. Biol. 2010, 30, 781-786.

10. Sperry, W.M. Lipid excretion IV. A study of the relationship of the bile to the fecal lipids with special reference to certain problems of sterol metabolism. J. Biol. Chem. 1927, 71, 351-378.

11. Pertsemlidis, D.; Kirchman, E.H.; Ahrens, E.H., Jr. Regulation of cholesterol metabolism in the dog. I. Effects of complete bile diversion and of cholesterol feeding on absorption, synthesis, accumulation, and excretion rates measured during life. J. Clin. Invest. 1973, 52, 2353-2367.

12. Vrins, C.L. From blood to gut: Direct secretion of cholesterol via transintestinal cholesterol efflux. World J. Gastroenterol. 2010, 16, 5953-5957.

13. Groen, A.K.; Bloks, V.W.; Bandsma, R.H.; Ottenhoff, R.; Chimini, G.; Kuipers, F. Hepatobiliary cholesterol transport is not impaired in ABCA1-null mice lacking HDL. J. Clin. Invest. 2001, 108, 843-850.

14. Plosch, T.; Kok, T.; Bloks, V.W.; Smit, M.J.; Havinga, R.; Chimini, G.; Groen, A.K.; Kuipers, F. Increased hepatobiliary and fecal cholesterol excretion upon activation of the liver $\mathrm{X}$ receptor is independent of ABCA1. J. Biol. Chem. 2002, 277, 33870-33877.

15. Kruit, J.K.; Plosch, T.; Havinga, R.; Boverhof, R.; Groot, P.H.; Groen, A.K.; Kuipers, F. Increased fecal neutral sterol loss upon liver $\mathrm{X}$ receptor activation is independent of biliary sterol secretion in mice. Gastroenterology 2005, 128, 147-156.

16. Temel, R.E.; Brown, J.M. Biliary and nonbiliary contributions to reverse cholesterol transport. Curr. Opin. Lipidol. 2012, 23, 85-90. 
17. Van der Velde, A.E.; Brufau, G.; Groen, A.K. Transintestinal cholesterol efflux. Curr. Opin. Lipidol. 2010, 21, 167-171.

18. Brufau, G.; Groen, A.K.; Kuipers, F. Reverse cholesterol transport revisited: Contribution of biliary versus intestinal cholesterol excretion. Arterioscler. Thromb. Vasc. Biol. 2011, 31, 1726-1733.

19. Vrins, C.L.; Ottenhoff, R.; van den Oever, K.; de Waart, D.R.; Kruyt, J.K.; Zhao, Y.; van Berkel, T.J.; Havekes, L.M.; Aerts, J.M.; van Eck, M.; et al. Trans-intestinal cholesterol efflux is not mediated through high density lipoprotein. J. Lipid Res. 2012, 53, 2017-2023.

20. Temel, R.E.; Sawyer, J.K.; Yu, L.; Lord, C.; Degirolamo, C.; McDaniel, A.; Marshall, S.; Wang, N.; Shah, R.; Rudel, L.L.; et al. Biliary sterol secretion is not required for macrophage reverse cholesterol transport. Cell Metab. 2010, 12, 96-102.

21. Temel, R.E.; Tang, W.; Ma, Y.; Rudel, L.L.; Willingham, M.C.; Ioannou, Y.A.; Davies, J.P.; Nilsson, L.M.; Yu, L. Hepatic niemann-pick c1-like 1 regulates biliary cholesterol concentration and is a target of ezetimibe. J. Clin. Invest. 2007, 117, 1968-1978.

22. Grundy, S.M.; Metzger, A.L. A physiological method for estimation of hepatic secretion of biliary lipids in man. Gastroenterology 1972, 62, 1200-1217.

23. Mitchell, J.C.; Stone, B.G.; Logan, G.M.; Duane, W.C. Role of cholesterol synthesis in regulation of bile acid synthesis and biliary cholesterol secretion in humans. J. Lipid Res. 1991, 32, 1143-1149.

24. Van der Veen, J.N.; van Dijk, T.H.; Vrins, C.L.; van Meer, H.; Havinga, R.; Bijsterveld, K.; Tietge, U.J.; Groen, A.K.; Kuipers, F. Activation of the liver X receptor stimulates trans-intestinal excretion of plasma cholesterol. J. Biol. Chem. 2009, 284, 19211-19219.

25. Vrins, C.L.; van der Velde, A.E.; van den Oever, K.; Levels, J.H.; Huet, S.; Oude Elferink, R.P.; Kuipers, F.; Groen, A.K. Peroxisome proliferator-activated receptor delta activation leads to increased transintestinal cholesterol efflux. J. Lipid Res. 2009, 50, 2046-2054.

26. Jakulj, L.; Vissers, M.N.; van Roomen, C.P.; van der Veen, J.N.; Vrins, C.L.; Kunne, C.; Stellaard, F.; Kastelein, J.J.; Groen, A.K. Ezetimibe stimulates faecal neutral sterol excretion depending on abcg8 function in mice. FEBS Lett. 2010, 584, 3625-3628.

27. Sokolovic, M.; Sokolovic, A.; van Roomen, C.P.; Gruber, A.; Ottenhoff, R.; Scheij, S.; Hakvoort, T.B.; Lamers, W.H.; Groen, A.K. Unexpected effects of fasting on murine lipid homeostasis - transcriptomic and lipid profiling. J. Hepatol. 2010, 52, 737-744.

28. Li, X.; Zhang, S.; Blander, G.; Tse, J.G.; Krieger, M.; Guarente, L. SIRT1 deacetylates and positively regulates the nuclear receptor LXR. Mol. Cell 2007, 28, 91-106.

29. Francis, G.A.; Knopp, R.H.; Oram, J.F. Defective removal of cellular cholesterol and phospholipids by apolipoprotein A-I in tangier disease. J. Clin. Invest. 1995, 96, 78-87.

30. Brunham, L.R.; Kruit, J.K.; Pape, T.D.; Parks, J.S.; Kuipers, F.; Hayden, M.R. Tissue-specific induction of intestinal ABCA1 expression with a liver $\mathrm{X}$ receptor agonist raises plasma HDL cholesterol levels. Circ. Res. 2006, 99, 672-674.

31. Rader, D.J.; Tall, A.R. The not-so-simple HDL story: Is it time to revise the HDL cholesterol hypothesis? Nat. Med. 2012, 18, 1344-1346. 
32. Briand, F.; Naik, S.U.; Fuki, I.; Millar, J.S.; Macphee, C.; Walker, M.; Billheimer, J.; Rothblat, G.; Rader, D.J. Both the peroxisome proliferator-activated receptor delta agonist, GW0742, and ezetimibe promote reverse cholesterol transport in mice by reducing intestinal reabsorption of HDL-derived cholesterol. Clin. Transl. Sci. 2009, 2, 127-133.

33. Van der Veen, J.N.; Kruit, J.K.; Havinga, R.; Baller, J.F.; Chimini, G.; Lestavel, S.; Staels, B.; Groot, P.H.; Groen, A.K.; Kuipers, F. Reduced cholesterol absorption upon PPARdelta activation coincides with decreased intestinal expression of NPC1L1. J. Lipid Res. 2005, 46, 526-534.

34. Duval, C.; Chinetti, G.; Trottein, F.; Fruchart, J.C.; Staels, B. The role of PPARs in atherosclerosis. Trends Mol. Med. 2002, 8, 422-430.

35. Takahashi, S.; Tanaka, T.; Kodama, T.; Sakai, J. Peroxisome proliferator-activated receptor delta (PPARdelta), a novel target site for drug discovery in metabolic syndrome. Pharmacol. Res. 2006, 53, 501-507.

36. Kramer, D.K.; Al-Khalili, L.; Guigas, B.; Leng, Y.; Garcia-Roves, P.M.; Krook, A. Role of AMP kinase and PPARdelta in the regulation of lipid and glucose metabolism in human skeletal muscle. J. Biol. Chem. 2007, 282, 19313-19320.

37. Leibowitz, M.D.; Fievet, C.; Hennuyer, N.; Peinado-Onsurbe, J.; Duez, H.; Bergera, J.; Cullinan, C.A.; Sparrow, C.P.; Baffic, J.; Berger, G.D.; et al. Activation of PPARdelta alters lipid metabolism in $\mathrm{db} / \mathrm{db}$ mice. FEBS Lett. 2000, 473, 333-336.

38. Oliver, W.R., Jr.; Shenk, J.L.; Snaith, M.R.; Russell, C.S.; Plunket, K.D.; Bodkin, N.L.; Lewis, M.C.; Winegar, D.A.; Sznaidman, M.L.; Lambert, M.H.; et al. A selective peroxisome proliferator-activated receptor delta agonist promotes reverse cholesterol transport. Proc. Natl. Acad. Sci. USA 2001, 98, 5306-5311.

39. Sprecher, D.L.; Massien, C.; Pearce, G.; Billin, A.N.; Perlstein, I.; Willson, T.M.; Hassall, D.G.; Ancellin, N.; Patterson, S.D.; Lobe, D.C.; et al. Triglyceride: High-density lipoprotein cholesterol effects in healthy subjects administered a peroxisome proliferator activated receptor delta agonist. Arterioscler. Thromb. Vasc. Biol. 2007, 27, 359-365.

40. Altmann, S.W.; Davis, H.R., Jr.; Zhu, L.J.; Yao, X.; Hoos, L.M.; Tetzloff, G.; Iyer, S.P.; Maguire, M.; Golovko, A.; Zeng, M.; et al. Niemann-pick c1 like 1 protein is critical for intestinal cholesterol absorption. Science 2004, 303, 1201-1204.

41. Rera, M.; Bahadorani, S.; Cho, J.; Koehler, C.L.; Ulgherait, M.; Hur, J.H.; Ansari, W.S.; Lo, T., Jr.; Jones, D.L.; Walker, D.W. Modulation of longevity and tissue homeostasis by the drosophila PGC-1 homolog. Cell Metab. 2011, 14, 623-634.

42. Rera, M.; Azizi, M.J.; Walker, D.W. Organ-specific mediation of lifespan extension: More than a gut feeling? Ageing Res. Rev. 2012, in press.

43. Rogers, R.P.; Rogina, B. A gutsy way to extend longevity. Front. Genet. 2012, 3, 108.

44. Libina, N.; Berman, J.R.; Kenyon, C. Tissue-specific activities of C. Elegans DAF-16 in the regulation of lifespan. Cell 2003, 115, 489-502.

45. Casirola, D.M.; Lan, Y.; Ferraris, R.P. Effects of changes in calorie intake on intestinal nutrient uptake and transporter mRNA levels in aged mice. J. Gerontol. A Biol. Sci. Med. Sci. 1997, 52, B300-B310.

46. Weindruch, R.; Walford, R.L. The Retardation of Aging and Disease by Dietary Restriction; C.C. Thomas: Springfield, IL, USA, 1988; p. xvii. 
47. Picard, F.; Kurtev, M.; Chung, N.; Topark-Ngarm, A.; Senawong, T.; Machado De Oliveira, R.; Leid, M.; McBurney, M.W.; Guarente, L. SIRT1 promotes fat mobilization in white adipocytes by repressing PPAR-gamma. Nature 2004, 429, 771-776.

48. Rodgers, J.T.; Lerin, C.; Haas, W.; Gygi, S.P.; Spiegelman, B.M.; Puigserver, P. Nutrient control of glucose homeostasis through a complex of PGC-1alpha and SIRT1. Nature 2005, 434, 113-118.

49. Bogan, K.L.; Brenner, C. Nicotinic acid, nicotinamide, and nicotinamide riboside: A molecular evaluation of NAD+ precursor vitamins in human nutrition. Annu. Rev. Nutr. 2008, 28, 115-130.

50. Guarente, L.; Picard, F. Calorie restriction - the SIR2 connection. Cell 2005, 120, 473-482.

51. Ingram, D.K.; Anson, R.M.; de Cabo, R.; Mamczarz, J.; Zhu, M.; Mattison, J.; Lane, M.A.; Roth, G.S. Development of calorie restriction mimetics as a prolongevity strategy. Ann. N. Y. Acad. Sci. 2004, 1019, 412-423.

52. Colman, R.J.; Anderson, R.M.; Johnson, S.C.; Kastman, E.K.; Kosmatka, K.J.; Beasley, T.M.; Allison, D.B.; Cruzen, C.; Simmons, H.A.; Kemnitz, J.W.; et al. Caloric restriction delays disease onset and mortality in rhesus monkeys. Science 2009, 325, 201-204.

53. Fontana, L.; Meyer, T.E.; Klein, S.; Holloszy, J.O. Long-term calorie restriction is highly effective in reducing the risk for atherosclerosis in humans. Proc. Natl. Acad. Sci. USA 2004, 101, 6659-6663.

54. Qin, W.; Yang, T.; Ho, L.; Zhao, Z.; Wang, J.; Chen, L.; Zhao, W.; Thiyagarajan, M.; MacGrogan, D.; Rodgers, J.T.; et al. Neuronal SIRT1 activation as a novel mechanism underlying the prevention of alzheimer disease amyloid neuropathology by calorie restriction. J. Biol. Chem. 2006, 281, 21745-21754.

55. Cohen, H.Y.; Miller, C.; Bitterman, K.J.; Wall, N.R.; Hekking, B.; Kessler, B.; Howitz, K.T.; Gorospe, M.; de Cabo, R.; Sinclair, D.A. Calorie restriction promotes mammalian cell survival by inducing the SIRT1 deacetylase. Science 2004, 305, 390-392.

56. Canto, C.; Gerhart-Hines, Z.; Feige, J.N.; Lagouge, M.; Noriega, L.; Milne, J.C.; Elliott, P.J.; Puigserver, P.; Auwerx, J. AMPL regulates energy expenditure by modulating NAD+ metabolism and SIRT1 activity. Nature 2009, 458, 1056-1060.

57. Canto, C.; Jiang, L.Q.; Deshmukh, A.S.; Mataki, C.; Coste, A.; Lagouge, M.; Zierath, J.R.; Auwerx, J. Interdependence of AMPK and SIRT1 for metabolic adaptation to fasting and exercise in skeletal muscle. Cell Metab. 2010, 11, 213-219.

58. Yang, H.; Yang, T.; Baur, J.A.; Perez, E.; Matsui, T.; Carmona, J.J.; Lamming, D.W.; Souza-Pinto, N.C.; Bohr, V.A.; Rosenzweig, A.; et al. Nutrient-sensitive mitochondrial NAD+ levels dictate cell survival. Cell 2007, 130, 1095-1107.

59. Brenner, C. Evolution of NAD biosynthetic enzymes. Structure 2005, 13, 1239-1240.

60. Houtkooper, R.H.; Pirinen, E.; Auwerx, J. Sirtuins as regulators of metabolism and healthspan. Nat. Rev. Mol. Cell Biol. 2012, 13, 225-238.

61. Chalkiadaki, A.; Guarente, L. Sirtuins mediate mammalian metabolic responses to nutrient availability. Nature Rev. Endocrinol. 2012, 8, 287-296.

62. Nogueiras, R.; Habegger, K.M.; Chaudhary, N.; Finan, B.; Banks, A.S.; Dietrich, M.O.; Horvath, T.L.; Sinclair, D.A.; Pfluger, P.T.; Tschop, M.H. Sirtuin 1 and sirtuin 3: Physiological modulators of metabolism. Physiol. Rev. 2012, 92, 1479-1514. 
63. Purushotham, A.; Schug, T.T.; Xu, Q.; Surapureddi, S.; Guo, X.; Li, X. Hepatocyte-specific deletion of SIRT1 alters fatty acid metabolism and results in hepatic steatosis and inflammation. Cell Metab. 2009, 9, 327-338.

64. Qiang, L.; Wang, L.; Kon, N.; Zhao, W.; Lee, S.; Zhang, Y.; Rosenbaum, M.; Zhao, Y.; Gu, W.; Farmer, S.R.; et al. Brown remodeling of white adipose tissue by SIRT1-dependent deacetylation of PPARgamma. Cell 2012, 150, 620-632.

65. Purushotham, A.; Xu, Q.; Lu, J.; Foley, J.F.; Yan, X.; Kim, D.H.; Kemper, J.K.; Li, X. Hepatic deletion of SIRT1 decreases hepatocyte nuclear factor 1alpha/farnesoid X receptor signaling and induces formation of cholesterol gallstones in mice. Mol. Cell. Biol. 2012, 32, 1226-1236.

66. Ponugoti, B.; Kim, D.H.; Xiao, Z.; Smith, Z.; Miao, J.; Zang, M.; Wu, S.Y.; Chiang, C.M.; Veenstra, T.D.; Kemper, J.K. SIRT1 deacetylates and inhibits SREBP-1c activity in regulation of hepatic lipid metabolism. J. Biol. Chem. 2010, 285, 33959-33970.

67. Walker, A.K.; Yang, F.; Jiang, K.; Ji, J.Y.; Watts, J.L.; Purushotham, A.; Boss, O.; Hirsch, M.L.; Ribich, S.; Smith, J.J.; et al. Conserved role of SIRT1 orthologs in fasting-dependent inhibition of the lipid/cholesterol regulator SREBP. Genes Dev. 2010, 24, 1403-1417.

68. Shin, D.J.; Campos, J.A.; Gil, G.; Osborne, T.F. PGC-1alpha activates CYP7A1 and bile acid biosynthesis. J. Biol. Chem. 2003, 278, 50047-50052.

69. Bordone, L.; Cohen, D.; Robinson, A.; Motta, M.C.; van Veen, E.; Czopik, A.; Steele, A.D.; Crowe, H.; Marmor, S.; Luo, J.; et al. SIRT1 transgenic mice show phenotypes resembling calorie restriction. Aging Cell 2007, 6, 759-767.

70. Danielsen, E.M.; Hansen, G.H.; Rasmussen, K.; Niels-Christiansen, L.L.; Frenzel, F. Apolipoprotein A-1 (apoA-1) deposition in, and release from, the enterocyte brush border: A possible role in transintestinal cholesterol efflux (TICE)? Biochim. Biophys. Acta 2012, 1818, 530-536.

71. Francone, O.L.; Subbaiah, P.V.; van Tol, A.; Royer, L.; Haghpassand, M. Abnormal phospholipid composition impairs HDL biogenesis and maturation in mice lacking ABCA1. Biochemistry (Mosc.) 2003, 42, 8569-8578.

72. McNeish, J.; Aiello, R.J.; Guyot, D.; Turi, T.; Gabel, C.; Aldinger, C.; Hoppe, K.L.; Roach, M.L.; Royer, L.J.; de Wet, J.; et al. High density lipoprotein deficiency and foam cell accumulation in mice with targeted disruption of ATP-binding cassette transporter-1. Proc. Natl. Acad. Sci. USA 2000, 97, 4245-4250.

73. Singaraja, R.R.; Fievet, C.; Castro, G.; James, E.R.; Hennuyer, N.; Clee, S.M.; Bissada, N.; Choy, J.C.; Fruchart, J.C.; McManus, B.M.; et al. Increased ABCA1 activity protects against atherosclerosis. J. Clin. Invest. 2002, 110, 35-42.

74. Van der Velde, A.E.; Vrins, C.L.; van den Oever, K.; Seemann, I.; Oude Elferink, R.P.; van Eck, M.; Kuipers, F.; Groen, A.K. Regulation of direct transintestinal cholesterol excretion in mice. Am. J. Physiol. Gastrointest. Liver Physiol. 2008, 295, G203-G208.

75. Krause, B.R.; Hartman, A.D. Adipose tissue and cholesterol metabolism. J. Lipid Res. 1984, 25, 97-110.

76. Holst, D.; Luquet, S.; Nogueira, V.; Kristiansen, K.; Leverve, X.; Grimaldi, P.A. Nutritional regulation and role of peroxisome proliferator-activated receptor delta in fatty acid catabolism in skeletal muscle. Biochim. Biophys. Acta 2003, 1633, 43-50. 
77. Barish, G.D.; Narkar, V.A.; Evans, R.M. PPAR delta: A dagger in the heart of the metabolic syndrome. J. Clin. Invest. 2006, 116, 590-597.

78. Lee, C.H.; Chawla, A.; Urbiztondo, N.; Liao, D.; Boisvert, W.A.; Evans, R.M.; Curtiss, L.K. Transcriptional repression of atherogenic inflammation: Modulation by PPARdelta. Science 2003, 302, 453-457.

79. Stein, S.; Matter, C.M. Protective roles of SIRT1 in atherosclerosis. Cell Cycle 2011, 10, 640-647.

80. Feige, J.N.; Auwerx, J. Dissirting on LXR and cholesterol metabolism. Cell Metab. 2007, 6, 343-345.

81. Defour, A.; Dessalle, K.; Castro Perez, A.; Poyot, T.; Castells, J.; Gallot, Y.S.; Durand, C.; Euthine, V.; Gu, Y.; Bechet, D.; et al. Sirtuin 1 regulates SREBP-1c expression in a LXR-dependent manner in skeletal muscle. PLoS One 2012, 7, e43490.

82. Sokolovic, M.; Sokolovic, A.; Wehkamp, D.; Ver Loren van Themaat, E.; de Waart, D.R.; Gilhuijs-Pederson, L.A.; Nikolsky, Y.; van Kampen, A.H.; Hakvoort, T.B.; Lamers, W.H. The transcriptomic signature of fasting murine liver. BMC Genomics 2008, 9, 528.

83. Sokolovic, M.; Wehkamp, D.; Sokolovic, A.; Vermeulen, J.; Gilhuijs-Pederson, L.A.; van Haaften, R.I.; Nikolsky, Y.; Evelo, C.T.; van Kampen, A.H.; Hakvoort, T.B.; et al. Fasting induces a biphasic adaptive metabolic response in murine small intestine. BMC Genomics 2007, 8,361 .

84. Windmueller, H.G.; Spaeth, A.E. Identification of ketone bodies and glutamine as the major respiratory fuels in vivo for postabsorptive rat small intestine. J. Biol. Chem. 1978, 253, 69-76.

85. Canto, C.; Houtkooper, R.H.; Pirinen, E.; Youn, D.Y.; Oosterveer, M.H.; Cen, Y.; Fernandez-Marcos, P.J.; Yamamoto, H.; Andreux, P.A.; Cettour-Rose, P.; et al. The NAD(+) precursor nicotinamide riboside enhances oxidative metabolism and protects against high-fat diet-induced obesity. Cell Metab. 2012, 15, 838-847.

86. Yoshino, J.; Mills, K.F.; Yoon, M.J.; Imai, S. Nicotinamide mononucleotide, a key NAD(+) intermediate, treats the pathophysiology of diet- and age-induced diabetes in mice. Cell Metab. 2011, 14, 528-536.

87. Tavintharan, S.; Kashyap, M.L. The benefits of niacin in atherosclerosis. Curr. Atheroscler. Rep. 2001, 3, 74-82.

88. Altschul, R.; Hoffer, A.; Stephen, J.D. Influence of nicotinic acid on serum cholesterol in man. Arch. Biochem. Biophys. 1955, 54, 558-559.

89. Bitterman, K.J.; Anderson, R.M.; Cohen, H.Y.; Latorre-Esteves, M.; Sinclair, D.A. Inhibition of silencing and accelerated aging by nicotinamide, a putative negative regulator of yeast sir2 and human SIRT1. J. Biol. Chem. 2002, 277, 45099-45107.

90. Baur, J.A.; Pearson, K.J.; Price, N.L.; Jamieson, H.A.; Lerin, C.; Kalra, A.; Prabhu, V.V.; Allard, J.S.; Lopez-Lluch, G.; Lewis, K.; et al. Resveratrol improves health and survival of mice on a high-calorie diet. Nature 2006, 444, 337-342.

91. Lagouge, M.; Argmann, C.; Gerhart-Hines, Z.; Meziane, H.; Lerin, C.; Daussin, F.; Messadeq, N.; Milne, J.; Lambert, P.; Elliott, P.; et al. Resveratrol improves mitochondrial function and protects against metabolic disease by activating SIRT1 and PGC-1alpha. Cell 2006, 127, 1109-1122. 
92. Park, S.J.; Ahmad, F.; Philp, A.; Baar, K.; Williams, T.; Luo, H.; Ke, H.; Rehmann, H.; Taussig, R.; Brown, A.L.; et al. Resveratrol ameliorates aging-related metabolic phenotypes by inhibiting camp phosphodiesterases. Cell 2012, 148, 421-433.

93. Price, N.L.; Gomes, A.P.; Ling, A.J.; Duarte, F.V.; Martin-Montalvo, A.; North, B.J.; Agarwal, B.; Ye, L.; Ramadori, G.; Teodoro, J.S.; et al. SIRT1 is required for AMPK activation and the beneficial effects of resveratrol on mitochondrial function. Cell Metab. 2012, 15, 675-690.

94. Timmers, S.; Konings, E.; Bilet, L.; Houtkooper, R.H.; van de Weijer, T.; Goossens, G.H.; Hoeks, J.; van der Krieken, S.; Ryu, D.; Kersten, S.; et al. Calorie restriction-like effects of 30 days of resveratrol supplementation on energy metabolism and metabolic profile in obese humans. Cell Metab. 2011, 14, 612-622.

95. Yoshino, J.; Conte, C.; Fontana, L.; Mittendorfer, B.; Imai, S.; Schechtman, K.B.; Gu, C.; Kunz, I.; Rossi Fanelli, F.; Patterson, B.W.; et al. Resveratrol supplementation does not improve metabolic function in nonobese women with normal glucose tolerance. Cell Metab. 2012, 16, $658-664$.

96. Chung, S.; Yao, H.; Caito, S.; Hwang, J.W.; Arunachalam, G.; Rahman, I. Regulation of SIRT1 in cellular functions: Role of polyphenols. Arch. Biochem. Biophys. 2010, 501, 79-90.

(C) 2013 by the authors; licensee MDPI, Basel, Switzerland. This article is an open access article distributed under the terms and conditions of the Creative Commons Attribution license (http://creativecommons.org/licenses/by/3.0/). 